\title{
Free Opening Performance of Steel Ladle as a Function of Filler Sand Properties
}

\author{
Ricardo Thomé da Cruz ${ }^{a *}$, Gustavo Frassini Pelisser ${ }^{b}$, Wagner Viana Bielefeldt ${ }^{b}$, Saulo Roca Bragança \\ ${ }^{a}$ Laboratório de Materiais Cerâmicos - LACER, Federal University of Rio Grande do Sul - UFRGS, \\ Av. Osvaldo Aranha, 99/705, CEP 900135-190, Porto Alegre, RS, Brazil \\ ${ }^{b}$ Laboratório de Siderurgia - LASID, Federal University of Rio Grande do Sul - UFRGS, \\ Av. Bento Gonçalves, 9500/sector 6, CEP 91501-970, Porto Alegre, RS, Brazil
}

Received: June 17, 2015; Revised: November 16, 2015; Accepted: January 4, 2016

\begin{abstract}
The secondary steel refining process uses filler sand as a thermal insulating barrier that separates the liquid metal from direct contact with slide-gate system of the steel ladle. The effective use of this practice must provide a high free opening rate, impacting on increased productivity and quality of steel, reducing the number of stops, thermal loss and even the steel re-oxidation. Both operational parameters and material properties have influence on the free opening rate. In the present work, two chromite-silica sands were analyzed, and some composition changes were proposed. The properties of these materials and the relevant process parameters were evaluated according to the free opening rate under normal operational conditions. The increases in carbon content and in particle size were considered the main factors relating to the filler sand. The percentage of free opening is also strongly influenced by time and temperature of the steel contact.
\end{abstract}

Keywords: Filler sand, Free opening rate, Refractory, Steelmaking

\section{Introduction}

In an electric steelmaking, there are great concerns about the operational variables that limit production in the continuous casting process. This process consists of passing the steel ladle from tapping to teaming, until the formation of the semi-finished product. One of the major factors that can delay the process is called 'non-free opening' of the slide-gate system that block the flow of steel from the teaming ladle to the tundish. Eventually, the flow of steel can be re-established using an oxygen lance cutting process which, besides its intrinsic slowness, can cause damage to the refractory material and risks of operational safety.

In order to avoid the contact between molten steel and the slide-gate system, a granular refractory material is used, called 'filler sand'. Different types of filler sands can be employed into the inner area of the nozzle and the well block. Chromite based sands are one of the most widely used materials. Several operational variables and materials characteristics affect their performance ${ }^{1}$.

Important and necessary properties of the filler sands have already stated: refractoriness, particle-size distribution, particle-packing density, low thermal expansion, flowability, and above all, the capacity to form a sintered crust with an appropriate thickness when brought in direct contact with the molten metal ${ }^{2}$.

The ideal filler sand must have a balance between refractoriness and surface melting, producing a sintered surface but avoiding a very thick sintered layer. The formation of a thicker sintered layer requires a greater pressure to be broken, which difficult the free opening. On the other hand, the rapid sintering of the surface of the filler sand, favors the

*e-mail: thomedacruz@yahoo.com.br free opening, because it prevents the penetration of liquid steel into the inner area of the nozzle of the flow system ${ }^{3,4}$. In this way, temperature and contact time of the liquid steel with the filler sand play a decisive role in the performance of the system.

Farshidfar and Kakroudi ${ }^{5}$ studied the use of the chromite based sands in continuous casting process. Their best results were obtained with the appropriate particle size distribution that favors the flowability and the permeability factor of the filler sand. Particle size distribution has also a strong influence to promote the nozzle filler sand flowing when the sliding gate is opened ${ }^{6}$. The presence of carbon decreases wetting of the sands by liquid steel and concomitantly its penetration on the sand bed $^{7}$. The presence of graphite causes the freeze plane to move closer to the hot face, minimizing steel penetration ${ }^{7}$.

The present study aimed to improve the understanding of the operational variables and the materials properties of the filler sand in order to increase free opening efficiency. The free opening was evaluated considering particle size, flowability, chemical composition and microstructure after firing of different filler sands. Some parameters of the steel production process were considered in order to enrichment the study. Thus, free opening rate was evaluated as a function of contact time (molten steel/filler sand), process temperature and $\mathrm{wt} \% \mathrm{C}$ in the steel.

\section{Material and Methods}

Two commercial chromite filler sands (A1 and B1) from two different suppliers were selected for this work. Subsequently, based on the materials characterization, 
laboratory pre-tests and results from literature ${ }^{5-7}$, some modifications of the materials properties were proposed to both suppliers. Thus, two new chromite sands have been developed - A2: increase in carbon content and particle size; B2: increase in particle size. Therefore, the present study includes laboratory characterization and evaluation of the performance under operational conditions of four sands in the industry.

The filler sands were evaluated in a semi-integrated mini mill that produces long carbon steels especially for civil construction industry. The ladle has approximately $2.5 \mathrm{~m}$ height and 21.5 ton of steel production capacity.

X-ray fluorescence (Shimadzu spectrometer - 1800), X-ray diffraction (Philips X'Pert), particle size distribution (by sieve), flowability index (ratio between the mass poured and vibrated) were used to the characterization of the filler sands. The effect of sintering temperature on the materials was also analyzed: parts of filler sand ( 5 bodies) were prepared by uniaxial pressing, and fired at $1500^{\circ} \mathrm{C}$ in an electric furnace, so the porosity was measured (Archimedes test). This test and the microstructural analysis were related to materials particle size and carbon content.

Thermodynamic study was performed using FactSage 6.4 commercial software. A general description of the software and databases as well as its current modifications ${ }^{8}$ was provided by Bale et al., ${ }^{9}$ Specifically, the temperature and amount of liquid phase formation was investigated. The data were confronted to practical results by firing the samples at $1600^{\circ} \mathrm{C}$ in graphite crucibles in an electric furnace with argon atmosphere (LINN High Therm furnace HT-2100-Vac-Graphit-Special). These samples were analyzed in the scanning electron microscopy-SEM (Hitachi, TM3000).

The percentage of carbon in the tested materials can be considered too small to have significant influence on the formation of oxide phases (liquid and solid), from a thermodynamic point of view. The FactSage's simulations have not considered carbon dissolution in the liquid the formation, nor in the reaction/formation of any complex oxide phase combined with carbon. $\mathrm{CO}_{2}$ was regarded as gas phase, and so total carbon was not considered in the simulations.

As is known, in industrial conditions some process parameters cannot be modified. In the present study, the analysis of the results have not evaluated changes in the dimension and shape of the ladle nozzle, ladle capacity, amount of sand added, and others operational procedures typical of the mini mill were the data were obtained. The performance of the filler sand was evaluated considering approximated temperature and time of steel contact. In addition, the free opening rate also was evaluated as a function of time, temperature and $w t \% \mathrm{C}$ in the steel. The data of 6 months of production was considered. The free opening rate was calculated according to the ratio: $n^{\circ}$ of runs with free opening $/ n^{\circ}$ of the total runs. At least, 100 runs were used for each parameter (time, temperature and $w \mathrm{t} \% \mathrm{C}$ ) evaluated.

\section{Results and Discussion}

\subsection{Characterization of the filler sands}

Table I shows the chemical composition of the four filler sands tested in this work. Considering A1 to A2 an increase in $\% \mathrm{C}$ was realized. Others variations in chemical composition were a consequence of batch preparation by the suppliers. For example, it can be noted an increase in silica and a small decrease in chromium oxide content when $\mathrm{B} 2$ is compared to $\mathrm{B} 1$.

Therefore, besides the higher carbon content in sample A2, the main change (A1 to A2; B1 to B2) was in the particle size distribution. The percentages of medium size particles were increased and the percentages of fine particles were reduced (Table II).

Figure I shows the XRD analysis for one of the sands since the same pattern was observed for all samples. According to the obtained XRD results, the main phases are quartz $\left(\mathrm{SiO}_{2}\right)$ and magnesiochromite $\left((\mathrm{Mg}, \mathrm{Fe})(\mathrm{Cr}, \mathrm{Al})_{2} \mathrm{O}_{4}\right)$. This phase is a solid solution of $\mathrm{FeCr}_{2} \mathrm{O}_{4}$, a spinel compound usually referred as chromite ${ }^{5}$.

In function of the particle size distribution alteration, the flowability index (Table III) of A2 and B2 sands was improved, what means a higher flowability and a better filling capacity ${ }^{10}$.

A higher particle size also contributes to an increasing of the porosity of the sintered parts (pressed bodies). Table III also shows that the apparent porosity of the samples sintered at $1500^{\circ} \mathrm{C}$ increased slightly, comparing $\mathrm{A} 1$ to $\mathrm{A} 2$ and $\mathrm{B} 1$ to $\mathrm{B} 2$.

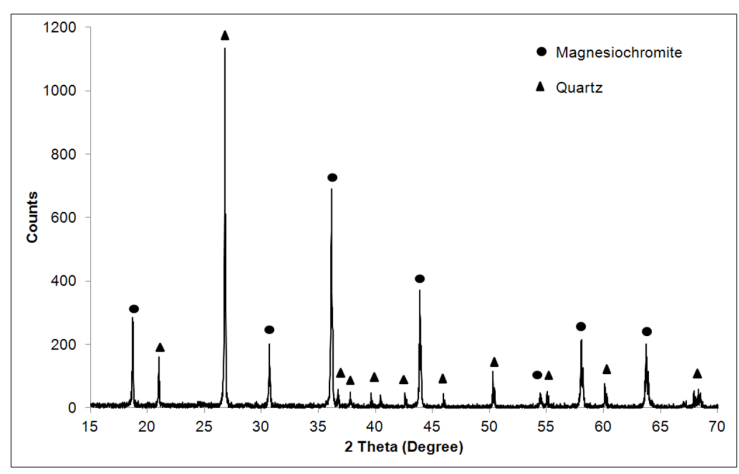

Figure I. XRD pattern of the A1 filler sand.

Table I. Filler sands chemical composition.

\begin{tabular}{cccccccccc}
\hline Supplier & Sand & $\mathbf{S i O}_{2}$ & $\mathbf{C r}_{2} \mathbf{O}_{3}$ & $\mathbf{F e}_{2} \mathbf{O}_{3}$ & $\mathbf{A l}_{2} \mathbf{O}_{3}$ & MgO & CaO & Others \\
\hline \multirow{2}{*}{$\mathrm{A}$} & $\mathrm{A} 1$ & 38.3 & 27.0 & 17.6 & 11.3 & 4.0 & 0.12 & 0.22 \\
& $\mathrm{~A} 2$ & 39.3 & 27.5 & 15.5 & 11.8 & 4.2 & 0.13 & 0.55 & 1.5 \\
\hline \multirow{2}{*}{$\mathrm{B}$} & $\mathrm{B} 1$ & 40.5 & 26.0 & 17.4 & 10.6 & 4.0 & 0.09 & 0.11 \\
& $\mathrm{~B} 2$ & 43.1 & 24.6 & 16.9 & 10.1 & 3.4 & 0.11 & 0.14 \\
\hline
\end{tabular}


Figure II shows the microstructures of the sands sintered at $1600^{\circ} \mathrm{C}$. The EDS analysis was used to help phase identification (tables inserted in the figures). It is observed that all aggregates (areas 1) are chromium oxide, the major refractory part of these materials. The aggregates are surrounded by a matrix of higher silica content (areas 2 ), which has a lower melting point, and has an aspect of a completely fused material. Areas 3 are a mixture of matrix and aggregates. As pointed out before (Table I), the EDS analysis also did not show big differences between the compositions of the four samples.

It can be observed that the microstructures of the sintered sands exhibit a good distribution of aggregates, which favors its behavior on duty. The cracks probably are originated due to difference in thermal expansion of the material phases,

Table II. Particle size analysis of the filler sand (A1, A2, B1 and B2).

\begin{tabular}{ccccc}
\hline \multirow{2}{*}{$\begin{array}{c}\text { Sieve mesh } \\
\text { (dpi mm) }\end{array}$} & \multicolumn{4}{c}{ Weight \% retained } \\
\cline { 2 - 5 } & $\mathbf{A 1}$ & $\mathbf{A 2}$ & $\mathbf{B 1}$ & B2 \\
\hline$-14+16 \#(1.3)$ & 1.5 & 1 & 4.5 & 5.3 \\
$-16+20 \#(1.125)$ & 1.1 & 1.3 & 2.6 & 3.4 \\
$-20+35 \#(0.67)$ & 12 & 23.6 & 8.7 & 11.0 \\
$-35+60 \#(0.375)$ & 46.3 & 51.4 & 39.2 & 54.3 \\
$-60+100 \#(0.199)$ & 38.8 & 22.1 & 44.8 & 24.9 \\
Mean diameter $(\mathrm{mm})$ & 0.29 & 0.35 & 0.29 & 0.34 \\
\hline
\end{tabular}

Table III. Flowability index (raw materials) and apparent porosity (after firing) of the filler sands.

\begin{tabular}{ccc}
\hline Sand & Flowability index & Apparent porosity \\
\hline A1 & 1.14 & $9.8 \pm 0.1$ \\
A2 & 1.11 & $12.1 \pm 0.3$ \\
B1 & 1.21 & $12.1 \pm 0.2$ \\
B2 & 1.15 & $13.2 \pm 0.3$ \\
\hline
\end{tabular}
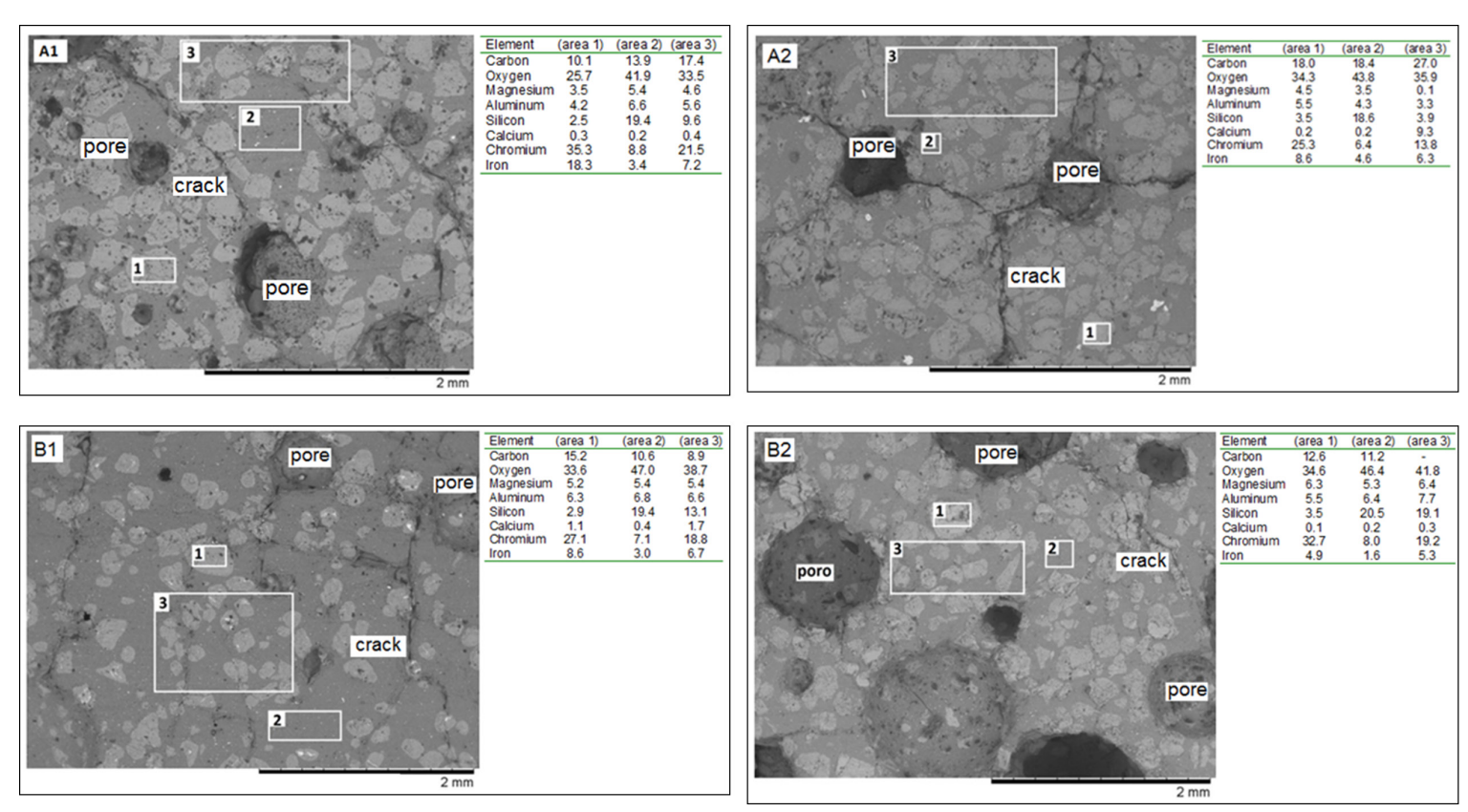

creating tensions that can break the part during cooling. In addition, these cracks demonstrate the weakness of the part, what can facilitate the free opening. The pores showed in Figure II are rounded and isolated what contributes to a higher thermal insulation.

The correct amount of aggregate and matrix phases is the key to optimize the performance of the filler sands. Thus, the sintering degree of the sands depends on raw materials quality and preparation, specifically, particle size and carbon content. In addition, it depends on the process variables, such as ferrostatic pressure, temperature, and contact time.

The fraction of liquid in filler sand has two effects. First, it promotes the formation of a sintered surface layer which prevents the penetration of the molten steel into the nozzle. Thus, a rapid formation of the sintered layer favors free opening: the lower the penetration of the steel inside the nozzle, the lower will be the pressure needed to break up the sintered layer. Second, an excessive sintering, as stated before, can hinder the opening of the nozzle.

Figure III shows the liquid fraction of the sands in function of temperature. The difference is small at $1600^{\circ} \mathrm{C}: \sim 8 \%$ for $\mathrm{A} 1$ to $\mathrm{A} 2$, and $5 \%$ for $\mathrm{B} 1$ to $\mathrm{B} 2$ formulations. As mentioned before, small variations in chemical composition (Table I), typically of batch preparation, may have small influence on sands behavior in operation. However, the results shown in Figure III pointed out that the liquid fraction can vary significantly with temperature change. This represents a variation of the sintering degree from top to bottom of the sands in the casting nozzle. From 1350 to $1500^{\circ} \mathrm{C}$ the variation of the liquid fraction is quite significant and very sensitive to temperature variation.

According to Figure III, A2 showed the highest liquid fraction at $1600^{\circ} \mathrm{C}$, and higher percentage of liquid phase at lower temperatures. The liquid phase formation at lower temperatures is essential to promote fast sintering on the sand layer surface. This sintered surface layer is important to

Figure II. Microstructures of the sintered sands (A1, A2, B1 and B2) at $1600^{\circ} \mathrm{C}$. EDS analysis in the tables. 


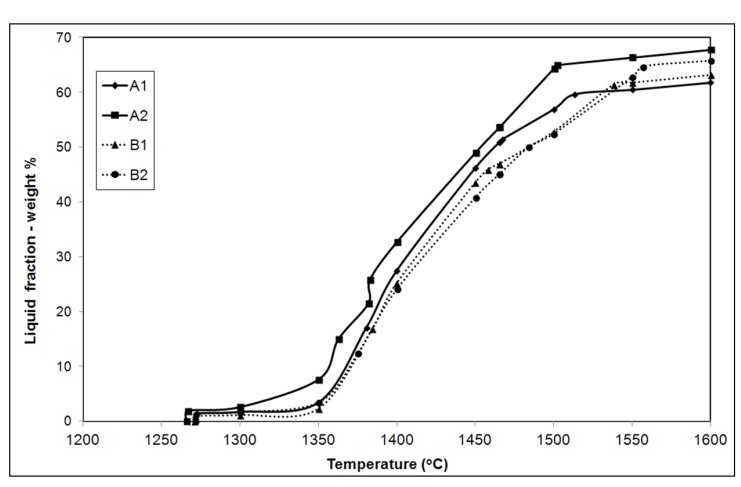

Figure III. FactSage simulation. Liquid fraction as a function of temperature for $\mathrm{A} 1, \mathrm{~A} 2, \mathrm{~B} 1$ and $\mathrm{B} 2$.

avoid the infiltration and solidification of liquid steel between sand particles and also, avoid the pull out of nozzle filler particles by liquid steel ${ }^{6}$. Nonetheless, the data in Table III had shown higher porosity for A2, what can be explained by a predominant factor: higher particle size (and lower surface area). A2 also have higher percentage of carbon. The presence of carbon may act as a sintering inhibitor, because it covers the particles with a thin layer, inhibiting direct contact between them ${ }^{6}$.

It can be summarized that according to Figure III liquid fraction has a strong dependence with temperature variation. Figure II showed that mechanical strength depends on the degree of sintering of the parts (eg. crack formation and pore size). Table III also revealed an increase in the porosity from A1 to A2 and B1 to B2. Chemical composition (Table I) have not shown significant variation and is a difficult parameter to be controlled at small levels. Therefore, particle size and carbon content are easier parameters to be manipulated and prove to be effective to control filler sand sintering behavior.

\subsection{Sands A1, A2, B1 and B2 in industrial tests}

The rate of free opening efficiency is shown in Table IV. The increase in free opening percentage was favored by the increase of particle size (Table II), disregarding the small differences in chemical composition. Among all the sands analyzed, A2 presented the best result. This can be attributed to the higher particle size, porosity after firing, flowability (Table III), and the higher carbon content.

Therefore, the breaking of the sintered layer in A2 was easier, resulting in a higher free opening. In this context, the highest free opening presented by A2 can be related to the specific material properties, according to the changes proposed, making this material more efficient compared to A1.

\subsection{Free opening rate as a function of process time and temperature.}

Temperature has a strong influence on the free opening, as previously mentioned. In Figure IV, it is observed that the curves of steel $\% \mathrm{C}$ and process temperature presented the same behavior in relation to free opening rate. Therefore, process temperature determines the percentage of free opening, since it has direct influence on the sintering degree of the sands. As already known, steels with higher percentage of carbon have lower teeming temperatures. Catchcart ${ }^{11}$ and

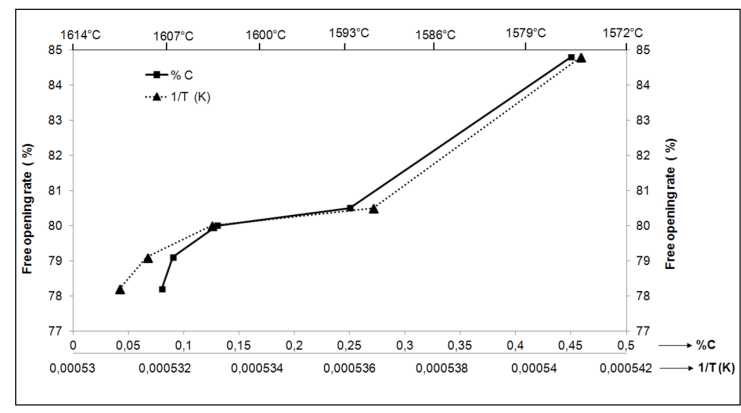

Figure IV. Free opening rate as a function of the steel $\% \mathrm{C}$ and process temperature. A1 sand.

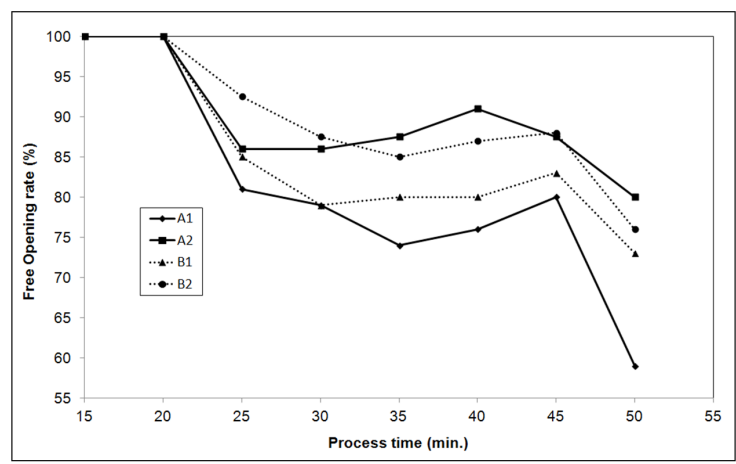

Figure V: Free opening rate as a function of the steel treatment time. A1, A2, B1 and B2 filler sands.

Table IV. Free opening rate (\%) according to the type of sand. Time, temperature and steel quality were fixed.

\begin{tabular}{ccccc}
\hline Sample & A1 & A2 & B1 & B2 \\
\hline$(\%)$ & 77.3 & 89.8 & 82.8 & 84.8 \\
\hline
\end{tabular}

Balagee $^{12}$ have shown in their works that steels with higher percentage of carbon had a higher free opening rate.

Figure $\mathrm{V}$ shows the tendency to decrease the free opening rate due to the increase of steel contact time. A longer steel treatment time means an increase on the thickness of the sintered layer. Therefore, the ferrostatic pressure required to open the steel flow becomes greater with time increasing. As expected, A2 showed a higher free opening rate comparing to the other sands. After $30 \mathrm{~min}$ the free opening rate decreased approximately $15 \%$. The effect of the steel processing time was also showed in the study of Catchcart ${ }^{11}$.

\section{Conclusions}

The results of this work show that the free opening rate depends on the operational parameters tested in this work, such as contact time between molten steel and filler sand, process temperature and $\mathrm{wt} \% \mathrm{C}$ in the steel, and physical and chemical properties of the filler sand. They control the sintering of the filler sand in the inner nozzle, which determines the free opening. Since not all operational 
parameters are susceptible to practical changes, the best type of sand to each steelmaking (and to each type of steel) should be optimized carefully.

A2 was the best filler sand for the steelmaking studied. It was formulated with higher percentage of carbon and higher particle size than the formulation in use. The carbon inhibits direct contact of the particles, and diminishes the wetting by molten metal, favoring the formation of weaker sintered materials. The particle size affects directly the sintering degree of the material. For both studied materials (A1 and B1) an increase in the particle size (A2 and B2) enhanced the apparent porosity after firing, what resulted in a higher free opening. The increased on porosity suggests

\section{References}

1. Tomba AG, Camerucci MA, Cavalieri AL. Ladle Filler Sand Evaluation [C]// Holger Evele, William D Faust. In: Proceedings of the Unified International Technical Conference on Refractories (UNITECR 05). Orlando: Curran Associates Publishers. 2005; $16 \mathrm{p}$.

2. Tseng T-T, Wu H-M, Chen C-N, Cheng C-C, Uan J-Y, Wu $\mathrm{W}$, et al. Refractory filler sands with core-shell composite structure for the taphole nozzle in slide-gate system of steel ladles. Ceramics International. 2012;38(2):967-971. doi:10.1016/j. ceramint.2011.08.017

3. Pan H, Ko Y. Constituents and characterization of packing sand for sliding gate systems for steel ladles. American Ceramics Society. 1981;60:736-739.

4. Chien YT, Pan HC, KO YC. Preparation and performance of packing sands for sliding-gate systems for steel ladles. Ironmaking Steelmaking. 1982;9:252-257 .

5. Farshidfar F, Kakroudi MG. Effect of chromite-silica sands characteristics on performance of ladle filler sands for continuous casting. Journal of Iron and Steel Research . 2012;19(3):11-13. the formation of a weaker sintered layer due to the increase of critical flaw size.

Particle size and carbon content are easier parameters to be handled and the results presented in this works proved that they have a strong influence in filler sand sintering behavior and, consequently, ladle free opening.

The temperature and treatment time of steel have strong influence on the sintering of filler sand. An increase in these parameters can decrease free opening. Considering longer steel treatment, A2 showed the best results. It keeps on an average of $80 \%$ of free opening rate even for $50 \mathrm{~min}$ of treatment in the ladle.

6. Seixas ML. Moisture influence on performance of nozzle filler for continuous casting of steel. In: XXXIX Steelmaking Seminar - International, 2008 May 12-16. Curitiba- PR.

7. Landy RA. Magnesia refractories. In: Schatcht CA, editor. Refractories Handbook. New York: Marcel Dekker; 2004.

8. Bale CW, Chartrand P, Degterov SA, Eriksson G, Hack K, Mahfoud RB, et al. FactSage thermochemical software and databases. Calphad. 2002;26(2):189-228. doi:10.1016/S03645916(02)00035-4

9. Bale CW, Bélisle E, Chartrand P, Degterov SA, Eriksson G, Hack K, et al. FactSage thermochemical software and databases. Recent developments. Calphad. 2009;33(2):295311. doi:10.1016/j.calphad.2008.09.009

10. Reed JS. Principles of ceramic processing. 2nd ed. New York: John Wiley \& sons; 1995.

11. Cathcart CR, Hole PJ, Minion RL. Ladle Free Open and Choke Free Improvement at Stelco Hilton Works. In: Steelmaking Conference Proceedings, 2000. http://digital.library.aist.org/ pages/PR-060-361.htm

12. Balagee SR, Bradley JE. Ladle free-opening performance at inland's steelmaking shops. In: Steelmaking Conference Proceedings, 1994. 